\title{
Desafios éticos nas relações entre enfermeiro e transexuais na Atenção Primária de
}

\section{Saúde}

Ethical challenges in the relationship between nurses and transsexual people in the Primary Health

Care

Retos éticos en la relación entre enfermeras y personas transexuales em la Atención Primária de Salud

Recebido: 18/01/2021 | Revisado: 21/01/2021 | Aceito: 25/01/2021 | Publicado: 27/01/2021

Denildo de Freitas Gomes

ORCID: https://orcid.org/0000-0002-9041-8894 Universidade Federal do Rio de Janeiro, Brasil

E-mail: enffreitas@hotmail.com

Enéas Rangel Teixeira

ORCID: https://orcid.org/0000-0002-1721-2056 Universidade Federal Fluminense, Brasil

E-mail: eneaspsi@hotmail,com

Marta Sauthier

ORCID: https://orcid.org/0000-0002-5153-0170

Universidade Federal do Rio de Janeiro, Brasil E-mail: martasauthier@hotmail.com

Alyson Gomes Gaia

ORCID: https://orcid.org/0000-0002-6967-0008 Hospital Universitário Clementino Fraga Filho, Brasil Email: alysong.gaia@gmail.com

\begin{abstract}
Resumo
O objetivo deste estudo foi identificar e discutir os possíveis fatores que dificultam ou fragilizam as relações entre o enfermeiro e o usuário transexual na Atenção Primária de Saúde, com foco direcionado à conduta ética e humanizada, assim como à influência de valores morais e ao autoconhecimento do enfermeiro acerca das suas dificuldades em lidar com esse tema. Trata-se de estudo original, exploratório com abordagem qualitativa. Os dados foram colhidos através de entrevista semiestruturada aplicada a 12 usuários transexuais entre dez/2018 e mar/2019. A coleta de dados ocorreu em um bairro do Município do Rio de Janeiro, tendo sido iniciada após a obediência de todos os aspectos ético-legais e normatizações relativas às investigações com seres humanos de acordo com a resolução n ${ }^{\circ} 466$ de 12 de dezembro de 2012 do Conselho Nacional de Saúde. Os resultados apontam para uma relação baseada no estigma e no preconceito, interferindo na autorrealização do usuário transexual - que se percebe em um ambiente por vezes hostil com negação de direitos básicos - e promovendo o aumento de vulnerabilidades e sofrimento pessoal advindos do não reconhecimento. Concluiu-se que o autoconhecimento do enfermeiro é fator fundamental para o estabelecimento de uma relação ética e humanizada, que efetive uma assistência direcionada às demandas de saúde dos usuários transexuais.
\end{abstract}

Palavras-chave: Pessoas transgênero; Enfermagem; Ética.

\begin{abstract}
This study aimed at identifying and discussing the possible factors to hinder or weaken the relationship between nurses and transsexual patients in the Primary Health Care, with a focus on ethical and humanized conduct, as well as the influence of nurses' moral values and self-knowledge about their difficulties in addressing such topic. This is an original, exploratory study using qualitative approach. Data were collected through semi-structured interviews applied to 12 transsexual patients from December/2018 to March/2019. Data collection took place in a district in the city of Rio de Janeiro, having started upon observing all ethical and legal aspects and regulations related to investigations with human beings in accordance with resolution No. 466, dated December 12, 2012, of the Brazilian National Health Council. The results suggest a relationship based on stigma and prejudice that interferes in the self-realization of transsexual patients - who see themselves in an environment that is sometimes hostile with the denial of basic rights and promotes an increase in vulnerabilities and personal suffering arising from the lack of recognition. We concluded that the nurses' self-knowledge is a key factor to establish an ethical and humanized relationship, thus providing assistance oriented to the health demands of transsexual patients.
\end{abstract}

Keywords: Transgender people; Nursing; Ethics. 


\section{Resumen}

Este estudio tuvo como objetivo identificar y discurtir los posibles factores que dificultan la relación entre enfermeras y pacientes transexuales em la Atención Primaria de Salud, con un enfoque em la conducta ética y humanizada, así como la influencia de los valores morales y autoconocimiento sobre sus dificultades para abordar este tema. Este es um estudio exploratorio original que usa un enfoque cualitativo. Los datos fueron recolectados mediante entrevistas semiestructuradas aplicado a 12 usuarios transexuales desde diciembre/2018 hasta marzo/2019. La recoleccíon de datos se llevó a cabo en un distrito de la ciudad de Rio de Janeiro, habiéndose iniciado con el cumplimiento de todos los aspectos éticos, legales y normativos relacionados com las investigaciones con seres humanos de acuerdo con la resolución n ${ }^{\circ}$ 466, del 12 de diciembre de 2012, de la Consejo de Salud. Los resultados sugierem una relación basada em el estigma y el prejuicio de interfiere em la autorrealización de los usuários transexuales -que se ven em un entorno en ocasiones hostil con la negación de derechos básicos-- y promueve un aumento de las vulnerabilidades y el sufrimiento personal derivado de la falta de reconocimiento. Concluimos que el autoconocimiento de las enfermeras es un factor clave para establecer una relación ética y humanizada, brindando así una asistencia orientada a las demandas de salud de los usuários transexuales.

Palabras clave: Personas transgénero; Enfermería; Ética.

\section{Introdução}

As questões de gênero emergem de forma recorrente nas discussões da sociedade. Ainda que se perceba uma grande evolução na aquisição de direitos sociais e legais pela população LGBTQIA+ (Lésbicas, Gays, Bissexuais, Transexuais, Queer, Intersexuais, Assexuais), é possível ainda, perceber uma disparidade no reconhecimento desse grupo por parte da sociedade.

As conquistas sociais muitas vezes estão à frente das representações culturais referentes a gênero construídos e incorporados por membros da sociedade. Essas representações ainda estão impregnadas de juízos de valores excludentes dificultando, assim, a compreensão de que os comportamentos esperados para as pessoas, os chamados papéis de gênero, não são inerentes ao sexo de nascimento, vão sendo moldados a partir das demandas sociais, econômicas, religiosas e culturais. (Rosa, Carvalho, Pereira, Rocha, Neves \& Rosa, 2019)

Os preconceitos e a estigmatização vividos pela população transexual estão, geralmente, sustentados por conceitos historicamente repetidos, notando-se, desta maneira, uma grande dificuldade em desvincular o gênero da orientação sexual dos indivíduos. Corroborando com esse pensamento alguns autores afirmam que, a identidade de gênero é referida como o gênero com o qual uma pessoa se identifica e se expressa, que pode divergir (transgênero) ou não (cisgênero) do gênero que lhe foi atribuído no seu nascimento, definido pelo sexo biológico. Esse conceito não prediz a orientação sexual, visto que esta consiste na vivência da sua sexualidade (heterossexual, homossexual, bissexual, pansexual ou assexual). Dentre as pessoas transgêneros, há as travestis e as mulheres transexuais, que, respectivamente, constroem uma expressão de gênero feminina e o reconhecimento como mulher transexual. (Silva, Abreu, Araújo, Alef, Sousa, Lyra \& Santos, 2020)

O modelo binário de gênero, aceito socialmente, reflete o masculino e o feminino ligados tanto à biologia, quanto a comportamentos e condutas depuradas no campo social e cultural. Esse modelo incide de maneira restritiva, a despeito da necessidade de compreender a variação de gênero como um fenômeno humano natural, livre da estigmatização e do caráter pejorativos ou patológicos que, historicamente, lhe foram construídos. Na perspectiva de Serra, Joca, Oliveira, \& Munguba (2020), precisamente por estar atrelada à subjetividade, o que indica sua pluralidade, a sexualidade não pode ser reduzida a papéis de gênero, estereótipos, normas ou convenções sociais.

Vale destacar ainda que, no que compete a identidade de gênero e a orientação sexual, estas foram reconhecidas como direitos humanos pela Organização das Nações Unidas e pela Organização dos Estados Americanos, desencadeando toda uma série de documentos que tratam da proteção e da não discriminação a esse grupo populacional. (Santos, Silva \& Ferreira, 2019).

Dessa forma, o ambiente de atenção à saúde ofertado a essa população, por direito, deve ser acolhedor, assim como para todos os grupos sociais. Deve ainda ser igualmente entendido como um conjunto de elementos externos aos indivíduos, 
que geram influências tanto sobre eles quanto sobre as pessoas com as quais interagem. (Freitas, Silva, Araújo \& Ferreira, 2013).

A ausência dessa percepção pode redundar em uma ambiência conflituosa entre os atores envolvidos, na qual minorias como a população LGBTQIA+, muitas vezes, encontram-se ou se percebem em um ambiente desrespeitoso e hostil no qual lhes são negados direitos básicos como, por exemplo, respeito ao nome social.

Relações desprovidas de elementos ético-legais conduzem a uma combinação de sentimento de menos valia exclusão e sofrimento, o que pode aumentar a vulnerabilidade desse usuário. Segundo Santos et. al, (2019), a população LGBTQIA+ encontra-se marginalizada nos serviços de saúde, devido ao preconceito e ao estigma que sofrem, que, aliados à falta de conhecimento dos prestadores de cuidado de saúde e à falta de sensibilidade às suas necessidades, acarretam prestação de serviços de má qualidade. Destarte, a atenção aos preceitos éticos no cuidado ao usuário torna-se uma questão importante para os profissionais de saúde que atuam em todos os níveis de atendimento. Logo, o enfermeiro deve permear sua conduta e assistência com vistas às determinações do seu código de ética profissional.

A completude de suas ações resulta em um atendimento humanizado, eficaz e de respeito à diferença. O contrário disso, a falha em perceber os problemas éticos vividos pelos enfermeiros da Atenção Primária de Saúde (APS), pode comprometer a qualidade da atenção à saúde prestada nesses serviços, ao impor o risco de rompimento do vínculo estabelecido entre os profissionais e os usuários. (Nora, Zoboli, Pavone, Vieira \& Dalla, 2015).

Diversos fatores podem interferir numa assistência que atenda às especificidades e ás singularidades dos transexuais. Para além do desconhecimento a respeito de gênero, observa-se a inserção de valores morais do profissional na relação estabelecida com esse usuário. Nessa linha de pensamento, diz-se que uma pessoa é ética quando se orienta por princípios e convicções e é moral quando age conforme costumes e valores consagrados. Assim, a moral, é parte da vida concreta e trata da prática real das pessoas que se expressam por costumes, hábitos e valores culturalmente estabelecidos. A moral consiste em um conjunto de normas ou regras admitidas em uma determinada época por um grupo de pessoas e que norteiam o comportamento humano. (Freitas, Oguisso \& Fernandes, 2010). Dessa forma, quando valores morais próprios, construídos socialmente são cristalizados, podem reverberar em atitudes profissionais contrárias ao preconizado pelo código de ética profissional.

A humanização e a ética se entrelaçam e se complementam numa relação entre os atores daquele cenário. Esses elementos sustentam e auxiliam a efetividade do estabelecimento das relações, onde o ambiente de saúde e acolhimento desta maneira se faria, dessa maneira, saudável. A humanização propõe a construção coletiva de valores que resgatem a dignidade humana na área da saúde e o exercício da ética, aqui pensada como um princípio organizador da ação. $\mathrm{O}$ agir ético, neste ponto de vista, refere-se à reflexão crítica que cada um de nós, profissionais da saúde, tem o dever de realizar, confrontando os princípios institucionais com os próprios valores, o modo de ser e pensar e agir no sentido do bem. ( Rios, 2009).

Para que se estabeleça uma relação ética e humanizada entre enfermeiros e transexuais, o diálogo é percebido como mola propulsora para que essa assistência apresente-se de forma promissora. Ademais, uma prática baseada em princípios éticos visa ao bem estar de todos os possíveis afetados, independentemente da posição social, política, religiosa ou econômica, buscando aquilo que é bom (sem prejuízos, injustiças, danos e sofrimentos) para todos. (Leal \& Rauber, 2012).

No contexto da discussão dessa produção, compreende-se a ética e a humanização imbricadas e obrigatórias para a prestação de uma assistência de qualidade, na qual a humanização possa ser compreendida como um vínculo entre profissionais e usuários, alicerçado em ações guiadas pela compreensão e pela valorização dos sujeitos, reflexo de uma atitude ética e humana. (Moreira, Meirelles, Dutra, Jaqueline \& Duarte, 2015).

Vale destacar que a questão que norteou essa pesquisa foi: quais são os fatores que podem interferir na conduta ética e humanizada nas relações entre enfermeiro e usuário transexual na APS? 
A partir dessa perspectiva, esse estudo tem como objetivo identificar e discutir os possíveis fatores que dificultam as relações entre enfermeiro e usuário transexual, referentes a conduta ética e humanizada na APS.

A grande motivação dessa investigação emergiu da experiência dos autores na assistência de enfermagem na APS, onde foi possível presenciar situações de desrespeito e privação de direitos vividos pelos usuários transexuais naquele ambiente. Desta forma, o impacto gerado frente ao conflito que se apresentava, projetou a necessidade de um melhor entendimento acerca daquele fenômeno.

Como referencial teórico, utilizou-se a Teoria do Reconhecimento de Axel Honneth, que explica o reconhecimento sustentado nas as esferas do amor, do direito e da solidariedade, solidificando-se, respectivamente, pelo desenvolvimento da autoestima através das relações familiares, pela aceitação social, pela inclusão em práticas institucionais e pela aceitação e convivência social satisfatória. (Honneth, 2011).

\section{Metodologia}

\section{Aspectos éticos}

Todos os aspectos ético-legais desta pesquisa, obedeceram às normatizações relativas às investigações com seres humanos de acordo com a resolução n466 de 12 de dezembro de 2012, do Conselho Nacional de Saúde (Brasil, 2012). O estudo em questão recebeu aprovação tanto do Comitê de Ética em Pesquisa (CEP) da instituição proponente, sob o $n^{\circ}$ 2.710.416, quanto do CEP da Instituição Coparticipante, que emitiu aprovação através do parecer nº 2.820 .474 .

\section{Tipo de estudo}

Trata-se de um estudo descritivo, exploratório com abordagem qualitativa, onde esses tipos de estudo auxiliaram tanto na compreensão da vivência do profissional no campo da Atenção Primária, quanto na importância na integralidade da assistência à população transexual. O método qualitativo é aquele, onde a importância está na interpretação por parte do pesquisador com suas opiniões sobre o fenômeno em estudo (Pereira; Shitsuka; Parreira \& Shitsuka, 2018)

Nesse contexto, a realidade é construída em conjunto entre pesquisador/a e pesquisado/a por meio das experiências individuais de cada sujeito. Sendo assim, os pesquisadores entendem que não há neutralidade e que estão, no processo da pesquisa, influenciando e sendo influenciados pelo que está sendo pesquisado. (Patias \& Hohendorff, 2019).

De forma congruente, a abordagem qualitativa, segundo a perspectiva de Minayo (2013), permite trabalhar com o universo de significados, motivos, aspirações, crenças, valores, atitudes, o que corresponde a um espaço mais profundo das relações, dos processos e dos fenômenos que não podem ser reduzidos à operacionalização de variáveis.

Cabe destacar que, a abordagem qualitativa se preocupa principalmente com o fenômeno que se apresenta ao observador, onde se aborda questões muito particulares, preocupando-se com uma realidade sem se voltar especificamente para quantificação das informações, mas sim para os significados imbricados ao objeto de análise. (Minayo, Deslandes, \& Gomes, 2015).

\section{Procedimentos metodológicos}

Os depoimentos retratados nesse estudo foram colhidos através da técnica de entrevista semiestruturada, com as pessoas transexuais residentes na área investigada. O roteiro de entrevista foi composto por questões abertas e estruturadas, que permitiram coletar, além de dados sóciodemográficos, informações importantes sobre a percepção do usuário transexual acerca da relação que se estabelece com o enfermeiro na APS.

A utilização da entrevista permite ao pesquisador obter aspectos subjetivos da pessoa investigada para, a partir daí, ampliar em uma dimensão mais coletiva. Ainda sobre os benefícios dessa técnica, pode-se afirmar que, se for bem realizada, 
permitirá ao pesquisador fazer uma espécie de mergulho em profundidade, coletando indícios dos modos como cada um daqueles sujeitos percebe e significa sua realidade e levantando informações consistentes que the permitam descrever e compreender a lógica que preside as relações que se estabelecem no interior daquele grupo. (Duarte, 2004).

\section{Cenário do estudo}

O cenário de pesquisa foram as Clínicas da Família adstritas à Coordenação da Área Programática (CAP) 5.3, localizadas em um bairro da Zona Oeste do Município do Rio de Janeiro. O bairro se localiza em uma região com ampla cobertura na Atenção Primária.

Cabe destacar que a exposição ao risco, tanto do entrevistador quanto do participante da pesquisa, motivada por situações que envolvem violência urbana, sendo esta uma característica da área utilizada para a pesquisa, levaram a várias desmarcações de entrevistas previamente agendadas, sendo este o principal fator limitador desse estudo.

\section{Fonte de dados}

Os participantes dessa pesquisa foram contactados através de registros do prontuário eletrônico utilizado pelas Unidades de Saúde, além dos usuários transexuais que procuravam os serviços para atendimento de suas demandas de saúde.

O número de participantes constituiu-se de 12 usuários que atenderam aos critérios de inclusão, a saber, usuários que se definiam pelo gênero transexual no preenchimento de dados pessoais no prontuário eletrônico; usuários transexuais que tenham utilizado os serviços da APS naquele campo de pesquisa e usuários que tenham passado por consulta de enfermagem agendada ou por porta de entrada.

É importante ressaltar que, todos os moradores na área investigada possuem registro nas Unidades de Saúde, independente de utilizá-la ou não, sendo esse procedimento realizado obrigatoriamente pelos Agentes Comunitários de Saúde, a fim de permitir a esse usuário o direito de acessar aos serviços no momento em que necessitar. Dessa forma, a exclusão deuse a partir da negativa desses usuários, independente dos motivos, em participar da pesquisa.

Em consonância com as determinações relacionadas à pesquisa com seres humanos, o inicio da coleta de dados se deu após a leitura do Termo de Consentimento Livre e Esclarecido (TCLE), juntamente com os participantes da pesquisa, e a anuência do mesmo. Destaca-se que o participante da pesquisa foi orientado quanto à possibilidade de desistência da entrevista a qualquer momento, sem nenhum prejuízo.

Para a preservação do anonimato do participante da pesquisa, os autores, em concordância com os entrevistados, optaram pelo uso do termo Participante da Pesquisa (PP) seguido pela numeração de acordo com a ordem em que as entrevistas foram realizadas.

\section{Coleta e organização dos dados}

O período de coleta de dados deu-se de dezembro de 2018 a março de 2019. Os encontros foram previamente agendados por telefone, de acordo com a disponibilidade do usuário. As entrevistam aconteceram nos consultórios das Clínicas da Família, com o consentimento prévio dos gerentes das unidades, preservando assim, a privacidade e o conforto dos participantes.

O número de participantes limitou-se a 12 pessoas pela saturação de dados, onde a forma de utilização mais comum do critério de saturação refere-se à aplicação de entrevistas semiestruturadas de forma sequencial, com respostas em aberto. Desse modo, foram identificados os tipos de resposta, conteúdos significativos e que se repetiram. Nesse sentido, quando nenhuma nova informação ou nenhum novo tema é registrado nos conteúdos dos dados, identifica-se o ponto de saturação. (Nascimento, Souza, Oliveira, Moraes, Aguiar, \& Silva, 2018). 
O tempo médio de cada entrevista foi de 60 minutos, totalizando 12 horas. Todas as entrevistas foram gravadas em mídia digital e transcritas pelo pesquisador. As gravações foram arquivadas e serão guardadas por um período de 5 anos.

\section{Análise dos dados}

Com relação aos dados derivados das questões abertas, utilizou-se a técnica de análise de conteúdo do tipo temática, de modo que os dados foram lidos, relidos e agrupados em núcleos de sentido que emergiram a partir da frequência em que apareciam nas falas dos depoentes. Assim a análise seguiu as seguintes fases: $1^{\circ}$ a pré-análise: objetivou a organização do material de análise para que o pesquisador pudesse conduzir as operações subsequentes; $2^{\circ}$ a exploração do material: referindose à aplicação das técnicas de análise no corpus como a codificação e a categorização; $3^{\circ} \mathrm{o}$ tratamento dos resultados, a inferência e a interpretação. (Bardin, 2011).

Do resultado da codificação e análise das transcrições, emergiram duas categorias temáticas, a saber: I Categoria temática: A percepção do corpo negligenciado através da invisibilidade: o predomínio do não reconhecimento e II Categoria temática: Enfermeiro e usuário transexual: uma relação frágil. Destaca-se que, as categorias citadas, foram analisadas e discutidas à luz da Teoria do Reconhecimento de Axel Honneth já referenciada.

\section{Resultados}

\section{Perfil sóciodemográfico}

Com o objetivo de uma melhor contextualização do usuário transexual participante desta pesquisa e morador na área programática investigada, os autores consideraram a importância de uma síntese dos resultados sóciodemográficos apresentados a seguir.

Quanto a faixa etária dos participantes da pesquisa, a idade variou entre 21 e 50 anos, sendo o maior percentual equivalente entre 21 e 40 anos. Com relação à profissão, houve uma grande diversificação de categorias profissionais: Professora (Rede Pública); Cabeleireira; Gestão de turismo; Autônomo; Auxiliar de cozinha; Auxiliar de limpeza; Promoter de eventos. O maior percentual relacionado a esse dado foi de $18 \%$ cabeleireira e $18 \%$ Auxiliar de cozinha.

Com relação à renda familiar, o maior percentual foi de $46 \%$, equivalente a menos de 01 salário mínimo, seguido de $27 \%$ até 02 salários mínimos e $27 \%$ maior que 02 salários. Vale destacar que a renda familiar dos depoentes está diretamente relacionada ao grau de instrução e ao estado civil declarado, cujo percentual foi de $30 \%$ das depoentes casadas e $70 \%$ solteiras.

\section{Categoria temática: A percepção do corpo negligenciado através da invisibilidade: o predomínio do não reconhecimento}

As falas das depoentes revelam explicitamente uma percepção de invisibilidade dentro das políticas públicas de saúde implementadas na área investigada. Essa percepção fica evidenciada pelo entrevistador, até mesmo na forma como as respostas são proferidas, ou seja, elas mostram uma sensação de inexistência em um contexto social que lhe garanta direitos sociais.

Recortes de falas como:

"Os transexuais não são vistos, mesmo a gente procurando a área de saúde, a gente vai, mas não tem uma coisa voltada, um serviço especial néh."(PP 07) "A maioria das meninas que fazem hormônio dentro de casa. Eu acho que os trans não tem visibilidade na área de saúde."(PP 11) ou "Quem poderia tá passando pra gente o aprendizado prefere se calar, então ou eu faço por mim ou vou ficar esperando ser mal tratada numa clínica ou onde for, então eu vou me virar sozinha. "(PP 06), denotam, nas entrelinhas, uma sensação de abandono e invisibilidade que interferem na saúde psicoemocial desse usuário. 
Nesse sentido, ainda que essa população não faça uma correlação imediata, emergem desses depoimentos uma atitude de negligência advinda da invisibilidade e do não reconhecimento dessa população como sujeitos de direitos aos serviços de saúde. Produções atuais corroboram com o pensamento de que a atuação da enfermeira na Assistência Primária de Saúde, como membro de uma equipe de Saúde da Família, implica no desempenho de funções pautadas nos princípios do Sistema Único de Saúde que, por princípio, não admite exclusões de qualquer natureza e tem o dever de promover a equidade. (Santos et.al., 2019).

Os fragmentos destacados mostram, ainda, uma percepção de que um corpo modificado, ou o desejo de fazê-lo, talvez não seja reconhecido como fonte identitária do usuário transexual, sendo, portanto, alijado de processos de trabalho que abordem o cuidado integral a população LGBTQIA+.

Expressões como: "Em relação aos enfermeiros, não tive orientação na minha época quanto aos riscos e efeitos colaterais das medicações porque muitos deles não sabem, porque na faculdade deles não abrange, então é um conhecimento que se você não correr atrás você não vai ter." (PP 09), “"Eu não acredito que nem médico e nem enfermeiro seriam capazes de me informar de nada sobre minha situação. A enfermeira não sabia, nem que fazia encaminhamento, tanto que ela me passou pro médico e ninguém sabia nada, ninguém sabia o que fazer na clínica da família." (PP 05), "Nunca fui orientada pra nada, quando eu virei trans eu sempre quis botar, como botei silicone injetável. A gente pede até a Deus pra não ficar doente." (PP 02), apontam para experiências individuais de desamparo dentro do sistema e risco de aumento da vulnerabilidade dessa população, construindo ainda, a percepção de que nenhum profissional é capaz, ou tem competência técnica, de atender a suas necessidades.

A análise das falas dos depoentes permitiu aos pesquisadores induzir que, na visão desse usuário, o enfermeiro ainda desenvolve um papel inexpressivo no que tange as necessidades de saúde dos transexuais. Esse papel coadjuvante desenvolvido pelo enfermeiro no cuidado, relacionado a essa população, talvez seja oriundo de desconhecimento acerca das necessidades subjetivas e específicas que esses usuários demandam.

Nesse contexto, a literatura atual já assevera que os enfermeiros e outros profissionais de saúde desconhecem a população transgênero e [...] precisam desenvolver competências culturais no que diz respeito à transgeneridade e reconhecer que as pessoas trans possuem uma cultura única. A invisibilidade trans provoca efeitos negativos aos cuidados de saúde prestados a essa população. (Rosa, Carvalho, Pereira, Rocha, Neves \& Rosa, 2019).

\section{Categoria temática: Enfermeiro e usuário transexual: uma relação frágil}

Através da análise do conteúdo das falas: "Depois da cirurgia eu tive sangramento na primeira relação, o médico deixou de ser médico pra ser curioso: Olha como é? Nossa olha o canal, olha isso!! Olha, ela tem lábios!! Eu fiquei passada com aquilo, Eu falei: meu Deus do céu, onde eu estou? Quando eu fui ver todo mundo tava sabendo, o enfermeiro, as enfermeiras, eu via que havia necessidade de eles vê!Eu me senti muito constrangida."(PP12), "Fui humilhada na unidade básica, riem da sua cara entendeu. Eu quando fui tirar o silicone que rejeitou, ela falou pra todo mundo ouvir: ah isso são homens que querem ser mulher mas nunca consegue, metem no corpo e depois vem pra cá pra dar dor de cabeça pros outros, quem falou isso era uma enfermeira. Ninguém respeita." (PP05), emergem a percepção de desrespeito, preconceito, estigmatização, desconhecimento da diversidade de gênero e da construção do corpo como valor identitário, humilhação, abjeção do corpo transexual, desconhecimento da legislação quanto ao uso do nome social e inobservância dos preceitos éticos relacionados ao exercício da profissão.

No que se refere ao estabelecimento de uma relação ética e humanizada, os recortes evidenciam condutas e expressões proferidas pelo enfermeiro, que inviabilizam uma troca relacional que permita um resultado efetivo e eficaz. 
Conteúdos de falas como: "Na primeira vez na rede publica não consegui já me disseram que não faz porque a gente não é mulher, porque não pode ter seios, que não sei o que, como tem o preconceito ainda néh" (PP02), "A impressão que tive sobre os profissionais na saúde básica quando eu procurei foi muito ruim por conta do acolhimento, as pessoas não sabem acolher, principalmente quando você não tem a sua identidade resgatada néh. (PP 09)", "O enfermeiro me chamou pelo nome masculino, acho que jamais ele tinha que falar o nome no masculino."(PP 11) e "Já teve bastante funcionários que fazem uns preconceitos com a gente disfarçados de brincadeiras, mais pra querer mexer com o ego da gente, mexer no nosso interior, isso já aconteceu muito aqui dentro. A gente passa por certas coisas que a gente vai reivindicar e sai como errada" (PP 04), simbolizam a percepção de uma relação desprovida de respeito e humanização pelo usuário.

Os destaques apresentados mostram ainda, diversas palavras que reverberam na produção de sofrimento claramente declarados pela população estudada. Observa-se uma relação pautada pelo desrespeito, sustentada pela violação de um modelo relacional onde haja uma interligação da ética e humanização. $\mathrm{O}$ agir ético, neste ponto de vista, se refere à reflexão crítica que cada um de nós, profissionais da saúde, tem o dever de realizar, confrontando os princípios institucionais com os próprios valores. (Rios, 2009).

As relações fragilizadas no contexto da saúde entre enfermeiro e usuário transexual, nesse estudo, apresentam-se de uma forma claramente conflitante. A percepção de um atendimento baseado na sensação de menos valia por esse usuário, é construída pela conduta do profissional dentro das Unidades Básicas, sendo esta reversa ao comportamento profissional ético desejado. Dessa maneira, ressalta-se que, estando a enfermagem no bojo das profissões da área da saúde, a ética em seu contexto assistencial apresenta a finalidade de prover o respeito ao outro em todos seus aspectos, favorecendo o equilíbrio e a condição humana em todos os aspectos. (Barbosa, Rodrigues, Celino \& Costa, 2017).

\section{Discussão}

O paradigma do modelo binário, construído e estabelecido socioculturamente, ainda apresenta dificuldades em incorporar a visão plural de gênero, o que pode fomentar relações baseadas na violência interpessoal e na discriminação.

Por conseguinte, provocam-se disparidades na saúde e uma maior incidência de agravos, principalmente naqueles mais sensíveis à vulnerabilidade social e individual (Gomes, Murta, Facchini \& Meneghel, 2018), levando a uma inadequação de serviços e a um frágil reconhecimento dos membros dessa população como sujeitos de direitos.

No percurso da análise dos resultados apresentados, vislumbrou-se uma multiplicidade de fatores que poderiam estar subsidiando a fragilização na relação estabelecida entre os atores envolvidos.

Relacionados à primeira categoria temática, percebem-se uma relação desrespeitosa, nutrida de preconceito e uma certa abjeção pelo corpo transexual. Corpo abjeto seria o não inteligível, o corpo rechaçado e não percebido dentro da comunidade e das relações sociais, algo que não importa. Ampliando o conceito de abjeção. Afirma-se que, o abjeto relacionase a todo tipo de corpos cujas vidas não são consideradas 'vidas' e cuja materialidade é entendida como "não importante'[...] Então, não é que o impensável, que aquilo que não pode ser vivido ou compreendido não tenha uma vida discursiva; ele certamente a tem. Mas ele vive dentro do discurso como a figura absolutamente não questionada, a figura indistinta e sem conteúdo de algo que ainda não se tornou real. (Prins \& Meijer, 2002).

$\mathrm{Na}$ ideação social, a visão binária de gênero prevalece como única forma aceitável, de o indivíduo expressar sua sexualidade e afetividade. A desobediência dos padrões construídos socialmente permeia a conduta e o modelo relacional entre os membros da sociedade, promovendo vários tipos de vulnerabilidade, inclusive no campo da saúde. Nesse contexto, produções recentes analisam que gênero, é ao mesmo tempo, criativo e violento, onde corpos e culturas estão igualmente em jogo e são constantemente transformados, às vezes até sua destruição. Assim, os arranjos de gênero tanto podem ser fontes de prazer, reconhecimento e identidade, como fontes de injustiça e danos. (Gomes et. al, 2018). 
Dessa forma, entende-se o ser enfermeiro como fruto de uma construção histórica, técnica científica e social, mas que deve pautar sua prática profissional na ética, respeito, valorização do ser humano e solidariedade. Todavia, a prevalência de conceitos morais e sociais, ainda que de forma inconsciente, incrustados em sua formação pessoal, podem vir a desencadear atitudes preconceituosas no que tange à pluralidade de gênero.

Nesse sentido, entendendo o enfermeiro como ser unidual, podemos afirmar que, a compreensão de que o profissional, acima de tudo, também é um ser humano e, portanto, apresenta sentimentos e barreiras físicas, psicológicas e sociais que o impossibilitam, como qualquer um, de compreender e realizar determinadas ações, também deve ser levado em conta. (Oliveira, Garcia \& Toledo, 2017).

Outrossim, o autoconhecimento por parte do profissional torna-se fator fundamental na quebra de paradigmas e de conceitos históricos incrustados na sua formação pessoal. O conhecimento de suas forças e fraquezas pode permitir ao enfermeiro colocar-se no cuidado, percebendo o outro, usando terapeuticamente a si próprio. Esse conhecimento tem um espaço primário e central em todos os conhecimentos, assim a prática da Enfermagem é a expressão de conhecimento pessoal. (Madureira, 2004).

O autoconhecimento, portanto, mostrou-se imperativo pela compreensão de que o conhecimento pessoal é uma busca movida a partir do despertar do próprio ser humano onde, o conhecimento de si mesmo está na base do relacionamento que se estabelece com os outros, (Baixinho, Ferraz, Ferreira, \& Rafael, 2014). Logo, conhecer-se a si, facilitaria a aproximação do profissional com o usuário transexual, que passaria a enxergá-lo como um sujeito possuidor de direitos de vivenciar sua identidade de gênero e sua sexualidade, além de uma assistência de saúde que promovesse seu bem-estar físico e emocional,

Dentro do contexto da relação percebida através dos depoimentos, por vezes, percebe-se uma a ação de forças antagônicas. Se por um lado encontra-se a necessidade do autoconhecimento do enfermeiro com sua dificuldade em dissociarse da sua construção sociocultural, por outro, temos o usuário transexual lutando por reconhecimento e por um atendimento ético e humanizado.

Frente ao exposto, claramente estabelece-se um conflito nessa relação através de uma expectativa não correspondida. O usuário transexual que procura pelo serviço de saúde espera o respeito e atenção que todos os cidadãos de direito possuem, e que lhe são garantidos por lei.

Com relação às expectativas do usuário transexual, que entende seu corpo como forma de reconhecimento social dentro de sua identidade de gênero, corrobora-se com a afirmativa na qual tais expectativas estão ligadas na psique às condições da formação de identidade pessoal, de modo que elas retêm os padrões sociais de reconhecimento sob os quais um sujeito pode se saber respeitado em seu entorno sociocultural como um ser ao mesmo tempo autônomo e individualizado; se essas expectativas normativas são desapontadas pela sociedade, isso desencadeia exatamente o tipo de experiência moral que expressa no sentimento de desrespeito. (Honneth, 2015).

Ainda sob a luz da Teoria Honnethiana, entende-se que a subjetividade dos sujeitos envolvidos venha a ser fator preponderante nas relações construídas entre enfermeiro e usuário transexual. Essa compreensão auxiliaria o profissional a enxergar esse usuário como um ser único e com demandas específicas. De forma mais abrangente, o reconhecimento é entendido, por Honneth, como uma construção intersubjetiva, dialógica e histórica, por meio da qual os sujeitos buscam a sua realização em três domínios essenciais: o afeto, os direitos e a estima social, dos quais advêm, respectivamente, a autoconfiança, o autorrespeito e a autoestima. (Wernet, Mello \& Ayres, 2017).

Outrossim, a satisfação das expectativas desses usuários estabeleceria uma reciprocidade entre os envolvidos, o que se contraporia ao sentimento de menos valia. Nesse contexto, destaca-se que a autorrealização, por exemplo, é uma aspiração efetivamente reconhecida, aceita por outros, e não uma possibilidade abstrata. Autorrealização e reconhecimento são as duas faces de uma mesma realidade ética. (Abreu, 2019). 
Os recortes apresentados mostram uma relação fragilizada, e, dessa forma, entende-se a necessidade do conhecimento pessoal do enfermeiro acerca de situações muitas vezes relacionadas a sua visão social e de mundo. Esse conhecimento talvez permitisse ao profissional compreender as subjetividades de cada indivíduo, inclusive as suas próprias.

Nesse sentido, percebe-se o não reconhecimento desse usuário pela falta de informações concretas e disponíveis a essa população, interferindo diretamente na sua autorrealização que, como condição da vida ética, significa o suprimento generalizado de oportunidades de satisfação individual que cada sujeito deveria ser capaz de experimentar como uma realização prática de sua liberdade. Mas a autorrealização depende do reconhecimento, porque só somos capazes de nos experimentar como seres livres quando confrontados com outros humanos opostos. [...] Reconhecer é conhecer algo (as escolhas ou os direitos de uma pessoa, por exemplo) a partir de modos prevalecentes de interação social, independentemente de esforço político ou intelectual (Wernet et al, 2017).

Ademais, o experienciado pelos usuários transexuais como, maus tratos, denegação de direitos e desvalorização social, afeta a dignidade e impede ou limita a autorrealização do sujeito, o que poderia ser atenuado, portanto, através do reconhecimento, base para o estabelecimento de uma relação recíproca.

Ainda que se considere e a importância e a dificuldade do autoconhecimento do profissional, itens fundamentais para dirimir fragilidades na relação entre o enfermeiro e usuário transexual, os preceitos éticos legais não devem ser desconsiderados como base relacional. Cabe ressaltar que, atitudes profissionais que auxiliam na promoção da autorrealização desse usuário, através de uma conduta ética, estão explicitamente sugeridas pelo Conselho Federal de Enfermagem (COFEN) na Resolução Cofen n ${ }^{\circ}$ 564/2017, nos Princípios Fundamentais, a determina que: O profissional de Enfermagem atua com autonomia e em consonância com os preceitos éticos e legais, técnico-científico e teórico-filosófico; exerce suas atividades com competência para promoção do ser humano na sua integralidade, de acordo com os Princípios da Ética e da Bioética

Este estudo apresentou como limite em seu desenvolvimento alguns fatores relacionados à população e outro peculiar à área investigada. Os limites relacionados a população estão ligados à disponibilidade de horários, havendo repetidas desmarcações por motivos pessoais, ou mesmo sem contato prévio com o pesquisador. Quanto à área investigada, o fator limitante foi a violência local pelo domínio de facções criminosas, ocasionando desmarcações ou suspensões de entrevistas devido a situações inesperadas de confronto policial no local.

\section{Conclusão}

Os resultados e discussões dessa pesquisa convergiram para as questões que motivaram sua realização pelos autores. Frente a todo o exposto, notoriamente os usuários transexuais percebem-se em um ambiente, por vezes, hostil e com atuação de profissionais com alguma deficiência, técnica ou emocional, de suprir suas ansiedades quanto as demandas específicas relacionadas à sua condição de gênero.

Fato é que, os conflitos gerados no ambiente da APS relacionados à população em estudo, não se resumem à equipe de enfermagem, mas abrangem profissionais de todas as categorias que ali desempenham suas funções, pois paradigmas sociais relacionados à divergência de gênero influenciam na construção individual de todos os sujeitos em determinados recortes temporais.

A resposta da questão que norteou esse estudo apresentou-se de forma objetiva nas falas dos depoentes, sendo possível inferir inclusive sobre o não explicitado claramente, mas que estava contido nas entrelinhas das respostas.

Fatores como preconceito e estigmatização permeiam a relação entre o enfermeiro e o transexual, reverberando em expectativas frustradas do usuário que busca pela autorrealização e reconhecimento social. Dessa forma, percebe-se a importância da busca do autoconhecimento por esses profissionais para que se identifique possíveis dificuldades em lidar com questões sobre divergência de gênero. 
Ademais, outra fonte de conflito pode advir da inserção de valores morais pessoais do profissional no atendimento a esse usuário que podem se sobrepor a elementos éticos e humanizados, fundamentais para uma relação terapêutica.

A ausência de informações, orientações ou processos de trabalhos executados nas unidades de saúde remete o usuário transexual a um estado de invisibilidade e de não reconhecimento como um cidadão inserido na sociedade e que necessita de uma assistência ética e humanizada, capaz de auxiliá-los na sua autorrealização.

Entretanto, nessa relação conflituosa, percebe-se que o desrespeito, atitudes preconceituosas e desprovidas de empatia, podem estar sustentados pela falta de autoconhecimento do profissional em como lidar com algo que destoe de paradigmas construídos pela sociedade e cultura na qual está inserido. Dessa forma, parece primordial uma profunda reflexão sobre a importância e a atenção nas respostas, verbais ou não verbais, desses usuários frente a posições e condutas desse profissional.

A fragilidade na relação entre o usuário transexual e o enfermeiro na APS, traduzida nas falas das depoentes, é entrelaçada pela invisibilidade e pelo não reconhecimento desse usuário. A forma como esses fatores apresentam-se é através de uma atitude desumanizada, muitas vezes desprovida de ética, e que estigmatiza esse grupo social, desqualificando sua condição de gênero e a importância dada na construção do corpo transexual como forma de identidade desse usuário.

Entende-se como um fator importante, que venha a contribuir para o desenvolvimento da enfermagem frente a essa população, a busca do autoconhecimento pelo profissional, na qual o conhecimento acerca de suas fragilidades e subjetividades como um ser construído sócioculturamente, talvez colabore para a compreensão do outro, sendo possível então, o estabelecimento de uma relação intersubjetiva.

Esse processo de desenvolvimento do conhecimento de si enquanto um ser social poderia reduzir dificuldades, fragilidades e limitações nas relações desenvolvidas entre o profissional e o usuário transexual, além de corroborar para uma atitude em que o autoconhecimento viabilizaria o reconhecimento desse usuário como um cidadão com importância na sua diversidade, e com direitos sociais.

A garantia desses direitos embasaria uma relação ética, permitindo a efetivação de cuidados humanizados que possam dirimir sofrimentos e vulnerabilidades. Para tanto, os autores entendem a necessidade de, futuramente, ampliar as pesquisas relacionadas a essa temática, objetivando sensibilizar os profissionais de enfermagem quanto à importância na construção de conhecimento acerca da diversidade de gênero.

Vislumbra-se ainda que, o lidar com a transexualidade talvez devesse ser incluído na formação do enfermeiro e na gestão do cuidado de enfermagem de forma mais efetiva, promovendo, por esse profiisonal, uma assistência sustentada por sua formação humana, ética e técnica, tornando-se capaz de estabelecer uma relação mais efetiva e inclusiva.

\section{Referências}

Abreu, J. M. M. de. (2019). Reconhecimento e diferença na teoria ética de Axel Honneth: uma questão em forma de ensaio. Revista da Faculdade de Direito do Sul de Minas. 35(1). 403-420. https://www.fdsm.edu.br/conteudo/artigos/3d130b702ea7ae937d80b3a540dc42f6.pdf

Baixinho, C. L., Ferraz, I. C. B., Ferreira, Ó. M. R., \& Rafael, H. M. da S. (2014). A arte e os padrões de aprendizagem de saber em enfermagem. Revista da Escola de Enfermagem da USP, 48 (spe2), 164-170. https://dx.doi.org/10.1590/S0080-623420140000800024

Barbosa, M. L.; Rodrigues, H. N. dos S., Celino, S. D. de M., \& Costa, G. M. C. (2017). Conhecimento de profissionais de enfermagem sobre o código de ética que rege a profissão. Rev baiana enferm. 31(4). epub21978. https://portalseer.ufba.br/index.php/enfermagem/article/view/21978

Bardin, L. (2011). Análise de conteúdo. Traduzido por Luís Antero Reto, Augusto Pinheiro. Edições

Brasil. Resolução n ${ }^{\circ}$ 466, de 12 de dezembro de 2012. Dispõe sobre as diretrizes e as normas regulamentadoras de pesquisa envolvendo seres humanos. Diário Oficial da União, Brasília, DF. https://conselho.saude.gov.br/resolucoes/2012/Reso466.pdf

Carper, B. (1978). Fundamental patterns of knowing in Nursing. Advances in Nursing Science. Aspen Publishers, Inc.

Conselho Federal de Enfermagem. (2017) Resolução COFEN nº 564/2017. Código de Ética dos Profissionais de Enfermagem. http://www.cofen.gov.br/resolucao-cofen-no-5642017_59145.html

Duarte, R.. (2004). Entrevistas em pesquisas qualitativas. Educar em Revista. (24), 213-225. https://doi.org/10.1590/0104-4060.357 
Freitas, F. D. S., Silva, R. N., Araújo, F. P., \& Ferreira, M. A. (2013). Ambiente e humanização: retomada do discurso de Nightingale na política nacional de humanização. Escola Anna Nery, 17(4), 654-660. https://doi.org/10.5935/1414-8145.20130008

Freitas, G. F., Oguisso, T., \& Fernandes, M. de F. P. (2010). Fundamentos éticos e morais na prática de enfermagem. Enfermagem em Foco; 1(3):104-108 DOI: $10.21675 / 2357-707 X .2010 . v 1 . n 3.37$

Gomes, R., Murta, D., Facchini, R., \& Meneghel, S. N. (2018). Gênero, direitos sexuais e suas implicações na saúde. Ciência \& Saúde Coletiva, 23(6), 19972006. https://doi.org/10.1590/1413-81232018236.04872018

Honneth, A. (2011). Luta por Reconhecimento: a gramática moral dos conflitos sociais. Repa L, tradutor. Editora 34.

Honneth, A. (2015). O direito da liberdade. [S. Krieger: Das Recht der Freiheit]. Martins Fontes.

Leal, D. F., Rauber, J. J. (2012). A concepção de ética dos profissionais de enfermagem. Rev Min Enferm, 16(4). 554563.http://www.reme.org.br/artigo/detalhes/561

Madureira, V. S..F. (2004). Os saberes da enfermagem. Revista Brasileira de Enfermagem, 57(3), 357-360. https://doi.org/10.1590/S003471672004000300021

Minayo M. C. S. (2013). O desafio do conhecimento: pesquisa qualitativa em saúde. (13a ed.), Hucitec.

Minayo, M. C. S, Deslandes, S. F., \& Gomes, R. (2015). Pesquisa social: teoria, método e criatividade. (34a ed.). Vozes.

Moreira, M. A. D., Meirelles, L. A. M., Dutra, F. B., E. de O. B., Jaqueline, B. V., \& Duarte, Marcella Costa Souto. (2015). Políticas públicas de humanização: revisão integrativa da literatura. Ciência \& Saúde Coletiva, 20(10), 3231-3242. https://doi.org/10.1590/1413-812320152010.10462014

Nascimento, L. de C. N., Souza, T. V..de, Oliveira, I. C. dos S., Moraes, J. R. M. M. de, Aguiar, R. C. B. de, \& Silva, L. F. da. (2018). Theoretical saturation in qualitative research: an experience report in interview with schoolchildren. Revista Brasileira de Enfermagem, 71(1), 228233. https://doi.org/10.1590/0034-7167-2016-0616

Nora, C. R. D., Zoboli, E. L. C. P., \& Vieira, M. (2015). Problemas éticos vivenciados por enfermeiros na atenção primária à saúde: revisão integrativa da literatura. Rev. Gaúcha Enferm. 36(1). 112-121. http://dx.doi.org/10.1590/1983-1447.2015.01.48809.

Oliveira, A. de, Garcia, A. P. R. F., \& Toledo, V. P. (2017). Padrões de conhecimento utilizados por enfermeiras no cuidado ao paciente no primeiro surto psicótico. Escola Anna Nery, 21 (3), e20170001. Epub 10 de julho de 2017. https://doi.org/10.1590/2177-9465-ean-2017-0001

Patias, N. D., Hohendorff, J. V. (2019). Critérios de qualidade para artigos de pesquisa qualitativa. Psicologia em Estudo, 24, e43536. Epub em 05 de dezembro de 2019. https://doi.org/10.4025/psicolestud.v24i0.43536

Pareira, A. S., Shitsuka, D. M., Parreira, F. J., \& Shitsuka, R. (2018). Metodologia da pesquisa científica. Santa Maria, RS: UFSM, NTE.e-book. Recuperado de: https://www.ufsm.br/app/uploads/sites/358/2019/02/Metodologia-da-Pesquisa-

Cientifica_final.pdf.

Pinto, A. C., Garanhani, M. L., França, T. E. de, \& Pierotti, I.. (2017). Conceito de ser humano nas teorias de enfermagem: aproximação com o ensino da condição humana. Pro-Posições, 28(Suppl. 1), 88-110. https://doi.org/10.1590/1980-6248-2015-0164

Prins, B. \& Meijer, I. C. (2002). Como os tornam materiais: entrevista com corpos de Judith Butler. Revista Estudos Feministas, 10(1), 155167. https://doi.org/10.1590/S0104-026X2002000100009

Rios, I. C.. (2009). Humanização: a essência da ação técnica e ética nas práticas de saúde. Revista Brasileira de Educação Médica, 33(2), 253261. https://doi.org/10.1590/S0100-55022009000200013.

Rosa, D. F., Carvalho, M. V. F., Pereira, N. R., Rocha, N. T., Neves, V. R., \& Rosa, A. S. (2019). Assistência de enfermagem à população transexual: os gêneros na perspectiva da prática profissional. Revista Brasileira de Enfermagem, 72 (Supl. 1), 299-306. https://doi.org/10.1590/0034-7167-2017-0644

Santos, J. S., Silva, R. N. da, \& Ferreira, M. de A.. (2019). Saúde da População LGBTI + na Atenção Básica à Saúde e a Inserção da Enfermagem. Escola Anna Nery, 23 (4), e20190162. Epub 14 de outubro de 2019. https://dx.doi.org/10.1590/2177-9465-ean-2019-0162

Serra, O. I, Joca T. T, Oliveira, A. R.M.N, Manguba, M. C. (2020). A pessoa com deficiência e os entrelaces com as questões de gênero e de sexualidade. Research, Society and Development, v. 9, n. 8, e728986157, 2020 (CC BY 4.0) | ISSN 2525-3409 | http://dx.doi.org/10.33448/rsd-v9i8.6157

Silva, R. G., Abreu, P. D., Araújo, E. C., S., Alef, D. S., Sousa, J. C., Lyra, J., \& Santos, C. B. (2020). Vulnerability in the health of young transgender women living with HIV/AIDS. Revista Brasileira de Enfermagem, 73(5), e20190046. https://dx.doi.org/10.1590/0034-7167-2019-0046

Wernet, M., Mello, D. F. de, \& Ayres, J. R. de C. M. (2017). Reconhecimento em Axel honneth: contribuições à pesquisa em saúde. Texto \& Contexto Enfermagem, 26(4), e0550017. https://dx.doi.org/10.1590/0104-070720170000550017 